\title{
How Gender Differences in Entitlement and Apprehension Manifest Themselves in Negotiation
}

\author{
Najib A. Mozahem ${ }^{1}$ (D) Moniat El Noufous K. El Masri ${ }^{2} \cdot$ Nazhat M. Najm$^{2}$. \\ Samah S. Saleh ${ }^{2}$
}

Accepted: 19 January 2021 / Published online: 31 January 2021

(c) The Author(s) 2021

\begin{abstract}
The gender difference in the propensity to initiate negotiation has been theorized to be mediated by three constructs: recognition of opportunities, entitlement, and apprehension. This study seeks to investigate whether differences in feminine and masculine traits can be used to explain gender differences in the three predictors of the propensity to initiate negotiations. Data was collected from 350 surveys distributed in Lebanon. Items were used to measure the constructs masculinity and femininity, as well as the three predictors of the propensity to initiate negotiation, namely Recognition of opportunities, Entitlement, and Apprehension. Confirmatory Factor Analysis was used to assess the validity of the measures, while structural equation modeling was used to investigate the relationship between the personality traits and the three constructs. Results indicate that masculinity enhances entitlement, which in turn leads to higher levels of negotiation while femininity enhances apprehension, which in turn leads to lower levels of negotiation. Both masculine and feminine traits were found to be positively related to the recognition of opportunities.
\end{abstract}

Keywords Gender $\cdot$ Negotiation $\cdot$ Masculinity $\cdot$ Femininity

Najib A. Mozahem

najib.mozahem@gmail.com; najib.mozahem@qu.edu.qa

Moniat El Noufous K. El Masri

elmasrimk@students.rhu.edu.lb

Nazhat M. Najm

najmnm@students.rhu.edu.lb

Samah S. Saleh

salehss@students.rhu.edu.lb

1 College of Business and Economics, Qatar University, P.O. Box 2713, Doha, Qatar

2 College of Business Administration, Rafik Hariri University, P.O. Box 10, Damour-Chouf 2010, Lebanon 


\section{Introduction}

Negotiation is essential for managers in a world where organizational challenges are becoming more frequent and more complex in nature (Neale and Bazerman 1992). Studies have shown that negotiators care more about their relative outcomes than their absolute outcomes (Blount and Bazerman 1996) and that they are overconfident (Bazerman et al. 2000) and egocentric (Thompson and Loewenstein 1992). This has led to the view that negotiation is a process of competition (Tsay and Bazerman 2009), even though a strategy that combines both competition and cooperation offers distinct advantages (Barnes 1981; Putnam 1990). As such, negotiation has been associated with masculine traits (Bowles and Kray 2013; Kray and Thompson 2004), with women being told that they should "lean in" and that they should "ask for it" (Babcock and Laschever 2009).

Previous studies investigating differences in negotiation between the two sexes have found that women negotiate less (Babcock and Laschever 2009) and that they set lower goals (Tellhed and Björklund 2011). Given that these differences were found to be context-dependent (Mazei et al. 2015), gender differences in negotiation have been attributed to gender-related differences in agentic and communal traits (Paddock and Kray 2011). This study investigates whether characteristics that are associated with traditional male/female gender roles help in understanding the differences in the propensity to initiate negotiation between the two genders. The study seeks to investigate whether differences in feminine and masculine traits can be used to explain gender differences in the three predictors of the propensity to initiate negotiations. More specifically, the study seeks to understand whether masculine traits have a positive effect on the predictors of the propensity to initiate negotiations while feminine traits have a negative effect on the predictors of the propensity to initiate negotiations.

\section{Background}

It is now well documented that there are significant gender differences in negotiation behavior (Babcock et al. 2006; Stuhlmacher and Walters 1999) and that these differences in behavior have a substantial effect on the careers of men and women (Bowles et al. 2005; Ely et al. 2014). Studies have found that women report greater anxiety than men about negotiation (Babcock et al. 2006), that they set lower goals for themselves during a negotiation (Eckel et al. 2008), and that they are less confident in their abilities (Niederle and Vesterlund 2007).

Although some studies have found that women are less likely than men to recognize an opportunity to negotiate (Babcock et al. 2006), there is strong evidence that suggests that the problem is not completely in women's inability to perceive opportunities or even in their lack of abilities to handle such situations. Instead, many studies have found that the main problem women face when it comes to negotiation is how they are viewed and treated should they choose to negotiate. For example, Bowles et al. (2007) found that women were penalized more than 
men if and when they choose to negotiate. The study also found that although women were less likely to negotiate when their counterpart was a male, they were as likely to initiate negotiations when faced with a female, thus indicating that the gender of the person evaluating them was the issue and not their ability to recognize the opportunity.

This negative reaction, or "social backlash," has now been well documented in a number of studies. Women suffer a backlash when they are perceived as acting in a masculine way (Rudman and Glick 2001; Von Hippel et al. 2011). Since negotiation is typically associated with masculine traits, women who initiate negotiations risk being viewed negatively. Amanatullah and Tinsley (2013) have found that women advocating for themselves are punished more than others. Pfafman and McEwan (2014) have documented how women learn to adopt what they called "strategic assertiveness," thereby allowing themselves to navigate the conflict between their gender and professional identities (Pfafman and McEwan 2014). Therefore, women are aware of this conflict and act accordingly. In support of this view, studies have found that women were more hostile (Stuhlmacher et al. 2007) and competitive (Walters et al. 1998) when their identities were hidden. When the negotiation context does not conflict with women's social role, women are more likely to behave assertively when negotiating (Amanatullah and Morris 2010) and to initiate negotiations (Small et al. 2007). A meta-analysis by Mazei et al. (2015) found that gender differences in negotiations are eliminated in such instances.

Given the above findings, Kray et al. (2004) have argued that the outcome of negotiation is affected by cognitive and motivational elements. This can be seen by the finding that in some cases, the activation of negative gender stereotypes can lead to women reacting against the stereotype by setting more aggressive goals (Kray et al. 2001). Kennedy and Kray (2015) have similarly noted that the issue is not one of competence. Instead, it is an issue of stereotypes and motivation, with women being underestimated and demotivated when it comes to negotiation. This multifaceted nature of negotiation has been incorporated into research that has concentrated on the process of negotiation, i.e., what happens after different parties sit at the negotiation table. Prior studies have tended to concentrate on the outcome of negotiation by concentrating on how participants choose to negotiate and on the outcome of the negotiation process. Babcock et al. (2006) have criticized this state of affairs and have called on researchers to pay more attention to the factors that lead individuals to choose to negotiate in the first place. This change of perspective will naturally lead researchers to address the different psychological and situational factors that might result in differences in the propensity to negotiate behavior since negotiation is no longer taken as a given. In a recent literature review of the topic, Kugler et al. (2018) have noted that the body of literature addressing gender differences in the initiation of negotiation is small despite the fact that it has recently started to attract more attention. The current literature pays more attention to situational factors that affect the decision of the individual in terms of choosing to negotiate or not. Such research has focused on the framing of the situation (Small et al. 2007), the sex of the opposite party (Eriksson and Sandberg 2012), and situational ambiguity (Kugler et al. 2018). Unlike previous studies, the present study seeks to incorporate the decision to initiate negotiations by using a multi-factor model that incorporates 
both the psychological predictors of the propensity to initiate negotiation and the act of negotiation itself.

\section{Purpose of the Study}

The purpose of this study is to investigate differences between individuals in the propensity to initiate negotiations and how these differences manifest themselves in the act of negotiation. While previous studies have investigated differences between gender groups, the present study seeks to investigate differences between individuals based on the socially constructed roles of masculinity and femininity.

Kolb (2009) has criticized the fact that previous studies have treated gender as a stable property, which has resulted in sex and gender being used interchangeably. By doing so, the cultural and institutional forces that create inequalities have been downplayed (Kolb 2009). Researchers today are more particular about the distinctions between the two terms. While sex refers to biological categorization, gender refers to cultural and psychological categorizations. For evolutionary psychologists, the term sex is adequate because, in their view, the observed differences between men and women are the result of evolutionary adaptations. These biological adaptations are the cause of the differences that are observed in all cultures (Buss 1995).

Sociological theories, on the other hand, focus on sociocultural determinants of gender role development (Bussey and Bandura 1999). These theories differentiate between sex and gender in that while sex is biologically determined, gender is socially constructed due to the fact that it "is a multidimensional construct that refers to the different roles, responsibilities, limitations, and experiences provided to individuals based on their presenting sex/gender" (Johnson and Repta 2012: 20-21).

This concept of gender roles is socially very important because, in many instances, success is defined as the proper alignment between the role and the individual's attributes (Eagly and Karau 2002). Individuals learn about gender roles through observing roles that are "commonly held by women versus men in a society" (Eagly and Wood 2016: 466). The observed gender differences tend to be ascribed to inherent differences in the natures of women and men. Subsequently, these gender roles are internalized and incorporated into people's self-concept, thereby influencing their behavior through the belief that behavior that is consistent with these roles results in social approval (Eagly and Wood 2016). Status construction theory (Ridgeway 1991) describes how nominal characteristics, such as gender, become connected with certain situational beliefs. The theory argues that implicit assumptions about the worthiness of given actors in an encounter can "provide the seeds from which more general assumptions develop about the relative worthiness and competence of whole categories of social actors" (Ridgeway et al. 1998: 333). Social roles consist of behavioral expectations for oneself and for others, depending on the social position of the person (Stuhlmacher and Linnabery 2013). Under the current social structure, men's role is associated with agency, while women's role is associated with communion (Eagly et al. 2000), where agency refers to focusing on achieving personal goals, while communion refers to engaging with others in relationships and in group memberships 
(Helgeson 1994). As a result, dominant behavior becomes associated with men, and subordinate behavior becomes associated with women (Eagly and Wood 1999). According to Eagly and Wood (1999), dominant behavior "is controlling, assertive, relatively directive and autocratic," while subordinate behavior is "more compliant to social influence, less overtly aggressive, more cooperative and conciliatory" (p. 5).

Previous research has found that negotiations are risky due to the fact that strong factors remain outside the direct influence of the negotiator (Bazerman et al. 2000). Studies have also found that negotiators care more about their relative outcomes than their absolute outcomes (Blount and Bazerman 1996), are overconfident in their abilities (Bazerman et al. 2000), and are egocentric (Thompson and Loewenstein 1992). Given the above, negotiation has been viewed as a competitive process (Tsay and Bazerman 2009) and has been associated with masculine traits (Kray and Thompson 2004). As noted by Kolb (2009), this notion that more aggressive behavior is better in negotiation remains unquestioned by many. Since agentic qualities are associated with successful negotiation (Kray et al. 2002), the female role is seen as being incongruent with the process of negotiation.

There is strong evidence within the negotiation literature that negotiation differences between men and women are a result of actors abiding by their social roles. Studies have shown that there are certain conditions under which the gap between women and men was reduced, eliminated, or even in some cases, reversed (Mazei et al. 2015). Bowles et al. (2005) found that women negotiated compensation agreements that were $18 \%$ higher when they were representing someone else, Amanatullah and Morris (2010) found that women advocating for another person negotiate more assertively than self-advocating women, while Bowles et al. (2007) found that participants in an experiment were less likely to work with women who initiated compensation negotiations. The explanation put forth for this finding is that negotiating on behalf of someone else is congruent with the female role since the role is seen as relationship-oriented; hence the female negotiators do not fear a social backlash. "When a woman negotiates on behalf of herself, assertive bargaining is encoded as incongruent with communal prescriptions of the feminine role. When a woman negotiates on behalf of others, it is encoded as congruent with communal femininity" (Amanatullah and Morris 2010: 256-257). Women's behavior in negotiation was also found to be statistically different from their "expected" behavior in virtual negotiations (Stuhlmacher et al. 2007). Therefore, when the biological sex of the participant was not evident, the participants behaved differently.

Support for social-role theories is also provided by studies that investigated the outcomes should women choose to "overstep" the boundaries of their roles. For example, should women choose not to act stereotypically, such as acting more aggressively, then they risk suffering from a social backlash (Rudman and Glick 2001). Amanatullah and Tinsley (2013) have found that when female negotiators violate role expectations, they tend to be characterized by negative masculine traits. Von Hippel et al. (2011) have also found that women that use a more masculine communication style are perceived as less warm and likable.

By incorporating gender as a social construct, researchers will be able to account for cultural and institutional forces. As such, this study seeks to 
investigate whether there is a relationship between masculinity and femininity on the one hand and between the predictors of the propensity to initiate negotiation on the other hand.

While most previous studies have concentrated on what happens at the negotiating table, little is known about the factors the lead individuals to initiate negotiation. This is unfortunate given the fact that failure to come to the negotiation table can adversely affect individuals (Volkema and Fleck 2012). In order to investigate the relationship between femininity and masculinity on the one hand, and the predictors of the propensity to initiate negotiations on the other hand, the present study will use items developed by Babcock et al. (2006) in order to measure recognition of opportunities, entitlement, and apprehension. In addition to being a tried and tested measure, this particular measure offers the distinct advantage of capturing three predictors of someone's likelihood to initiate negotiations.

In order for an individual to consider initiating a negotiation, he/she should first identify the situation as one that is negotiable. Babcock et al. (2006) have found that women are less likely than men to recognize an opportunity to negotiate. Their study, however, treated gender as a biological construct. Therefore, to extend their findings, this study seeks to investigate whether individuals with masculine traits are more likely to recognize an opportunity as one that is negotiable. Studies have suggested that masculine traits are positively correlated with an internal locus of control (Kapalka and Lachenmeyer 1988) and that among women, feminine sex-role orientation was positively correlated with an external locus of control (Kuther 1998). Since perceiving an opportunity to negotiate is positively influenced by having an internal locus of control (Babcock et al. 2006) the first hypothesis in this study is whether masculinity is positively correlated with the ability to recognize opportunity:

Hypothesis 1 Masculine traits are positively correlated with the ability to recognize opportunities to negotiate.

With regards to entitlement, as noted by Babcock et al. (2006), people who feel that they deserve to have more than they currently have will be more likely to take action while people who do not feel that they deserve more will be on average more satisfied with what they have and less likely to take action to improve their situation. Given that men traditionally occupy the higher levels of the social hierarchy, and since social comparisons are related to perceived fairness (Austin et al. 1980), men report a higher sense of entitlement than women (Bylsma and Major 1992; Hogue et al. 2007). Since individuals high on masculinity value productivity and task success (Desmarais and Curtis 1997), increasing levels of masculinity will lead to an increased sense of entitlement (McGann and Steil 2006), which will lead to an increase in the probability that they will take action to further their interest:

Hypothesis 2 Masculine traits are positively correlated with a higher sense of entitlement. 
Finally, apprehension refers to the negative feelings that an individual might have about either the process of negotiation or the outcomes or both. Brooks and Schweitzer (2011) have found that anxiety results in setting lower goals and obtaining lower outcomes. Higher levels of anxiety towards something can have a substantial effect on an individual's self-efficacy (Bandura 1977). As argued by social cognitive theory, people avoid activities that they believe, whether rightly or wrongly, exceed their capabilities, and they undertake activities that they believe lie within their capabilities (Bandura 1977). As discussed in the literature review, female negotiators have been found to set lower goals and to be less confident. Since negotiation is associated with masculine traits, and since success is defined as the alignment between the social role and the attributes associated with an individual (Eagly and Karau 2002), we would expect that individuals who score high on femininity will be more apprehensive to initiating negotiations, since they are overstepping their traditional social boundaries:

Hypothesis 3 Feminine traits are positively correlated with higher levels of apprehension towards initiating negotiations.

In addition to testing the above three hypotheses, this study will conclude by proposing a model that attempts to explain observed differences in the propensity to initiate negotiations with regards to the constructs Masculinity and Femininity. Using the model, we will investigate whether the three predictors of the propensity to negotiate do in fact enhance an individual's likelihood of engaging in negotiation behavior. In addition, the model will allow us to investigate whether the variable gender has direct effects on the predictors of the propensity to negotiate or whether the effect of gender is mediated by the constructs Masculinity and Femininity.

\section{Methods}

\subsection{Data Collection}

We distributed surveys in private companies in Lebanon, a country situated on the Mediterranean with a population of around 6 million, almost half of which are women. According to a report published by the World Economic Forum, the gender educational parity measure in the country is 0.959 , but the economic parity measure is only 0.44 (Leopold et al. 2016).

All companies where the surveys were distributed are all located in Saida, a city in the South of Lebanon. The companies included in the study included hospitals, schools, banks, and pharmacies. A total of 350 surveys were collected, with $194(55.43 \%)$ of the participants being female and $156(44.57 \%)$ being male. The average age of the respondents was 27.73 years, with a standard deviation of 6.16 . The oldest person was 64 years old, while the youngest was 
21. The average age of male respondents was 28.79 , while the average age of female respondents was 26.89 . The surveys were distributed physically, and one of the researchers was present in order to answer any queries that the respondents might have.

\subsection{Measures}

In order to test the hypotheses, we needed to measure masculinity, femininity, and the predictors of the propensity to initiate negotiations. In order to measure masculinity and femininity, respondents were asked to indicate to what extent the following traits applied to them using a scale of 1 (not at all) to 7 (applies to me a lot): assertive, affectionate, gentle, competitive, sympathetic, dominant, makes decisions easily, individualistic, compassionate, understanding, and sensitive. These 11 items were obtained from Bem's (1974) sex-role inventory. The masculine items were chosen in accordance with the findings from the literature review on agency and negotiation. Given that previous studies have found that negotiators are overconfident (Bazerman et al. 2000), the items makes decisions easily and dominant were chosen. The items competitive and individualistic were chosen in accordance with the finding that negotiators are egocentric (Thompson and Loewenstein 1992). The item assertive was chosen based on the finding that negotiators escalate their commitment to previous actions regardless of whether these actions were favorable or not (Bazerman and Moore 2008). All items reflect the view that agency is associated with behavior that is controlling, assertive, and autocratic (Eagly and Wood 1999). On the other hand, the feminine items were chosen in accordance with the fact that communal behavior includes engaging with others in relationships and in group memberships. As such, the items affectionate, gentle, sympathetic, compassionate, understanding, and sensitive all facilitate such communal behavior, which might lead an individual to place the other person's interest or feelings ahead of their own.

Although the scale reliability and validity have been supported by numerous studies conducted in different cultural contexts (Fontayne et al. 2000; Katsurada and Sugihara 1999; Özkan and Lajunen 2005), the present study will conduct confirmatory factor analysis on the scale items in order to establish its validity and reliability in the current context.

As previously stated, we used the items developed by Babcock et al. (2006) in order to measure the three predictors of the propensity to initiate negotiations. A total of 12 items with values between 1-strongly disagree and 7-strongly agree were used, with four items measuring the recognition of opportunities, three items measuring entitlement, and five items measuring apprehension. Table 1 displays a sample of two items used to measure each of the three constructs.

Finally, in order to measure an individual's actual negotiation behavior, we used a single item in which respondents were asked: "How often do you initiate negotiations with the people with whom you work." Respondents answered the question using a scale of 1 (never) to 7 (a lot). 
Table 1 Sample items used to measure the three predictors of propensity to negotiate (Babcock et al. 2006)

Recognition of opportunities

Most things are negotiable

There are many things available to people, if only people asked for them

Entitlement

I think situations should be changed to fit my desires

I usually feel that I've earned the right to have things go my way

Apprehension

I feel anxious when I have to ask for something I want

It always takes me a long time to work up the courage to ask for things I want

\subsection{Analysis}

This study utilizes a combination of confirmatory factor analysis (CFA) and structural equation modeling (SEM) in order to address the hypotheses. CFA was used in order to test the validity of the measures employed while SEM was used in order to investigate whether there was any relationship between the different constructs. One of the main advantages of using CFA as opposed to traditional methods such as multivariate analysis of variance is that in CFA, each item is allowed to have its own unique variance, thus resulting in better estimates of the latent variables (Acock 2013). Second, and crucially for studies that investigate group differences, CFA allows the researcher to use a structured means approach in order to test the equality of the means, thereby resulting in a more accurate test than is provided by multivariate analysis of variance (Thompson and Green 2006).

The goodness-of-fit of the models was measured using the comparative fit index (CFI), the root mean square error of approximation (RMSEA), and the standardized root mean square residual (SRMR). Models that are considered to have a reasonable fit have a CFI greater than 0.90, and RMSEA and SRMR less than 0.08. Models that have a CFI greater than 0.95, and RMSEA and SRMR values less than 0.05 are considered to be a well-fit model (Hu and Bentler 1999).

\section{Results}

\subsection{Construct Validity Using Confirmatory Factor Analysis}

\subsubsection{Model Fit}

We conducted CFA in order to assess the model fit of each of the constructs. Table 2 shows the results obtained for the two constructs, Masculinity and Femininity. All goodness-of-fit measures indicate that the model is well fit. In addition, all items have loadings that are significant at the $p<0.001$ level, with the magnitude of the 
Table 2 Results for CFA model for the latent variables Masculinity and Femininity

\begin{tabular}{|c|c|c|c|}
\hline \multicolumn{2}{|l|}{ Masculinity } & \multicolumn{2}{|l|}{ Femininity } \\
\hline Item & Standardized value & Item & Standardized value \\
\hline Assertive & $0.59 * * *$ & Affectionate & $0.67 * * *$ \\
\hline Competitive & $0.54 * * *$ & Compassionate & $0.72 * * *$ \\
\hline Dominant & $0.74 * * *$ & Gentle & $0.69 * * *$ \\
\hline Makes decisions easily & $0.57 * * *$ & Understanding & $0.57 * * *$ \\
\hline \multirow[t]{2}{*}{ Individualistic } & $0.48 * * *$ & Sympathetic & $0.68 * * *$ \\
\hline & & Sensitive & $0.61 * * *$ \\
\hline$\chi^{2}=3.82, p=0.58$ & & $\chi 2=9.29, p=0.41$ & \\
\hline RMSEA $=0.000$ & & RMSEA $=0.010$ & \\
\hline $\mathrm{CFI}=1.00$ & & $\mathrm{CFI}=1.00$ & \\
\hline $\mathrm{SRMR}=0.018$ & & $\mathrm{SRMR}=0.021$ & \\
\hline
\end{tabular}

$* * * p<0.001$

loadings being satisfactory. Cronbach's alpha was found to be 0.82 for Masculinity and 0.72 for Femininity.

Table 3 shows the results of the CFA on the three constructs Recognition, Entitlement, and Apprehension. Again we see that all loadings were significant at the $p<0.001$ level with the magnitude of the loadings being satisfactory. In the case of the constructs Recognition and Apprehension, it should be noted that the best-fit models included correlated error terms. For the construct Recognition, an extra correlation term was estimated for the error terms of the first and third items. As for the construct Apprehension, the model includes two correlations, the first between the second and fifth items and the second between the third and fourth items. Cronbach's alpha was found to be 0.86 for Recognition, 0.70 for Entitlement, and 0.69 for Apprehension.

\subsubsection{Gender Differences}

The next step after establishing the validity of the items used was to investigate whether there were gender differences in the means of any of the constructs. In order to conduct this mean test, we fit a model that fixes the mean of one of the groups at zero (women in our case), thus using that group as a reference, while allowing the mean of the other group to take on any value. This method allows us to calculate a $\mathrm{z}$-score in order to test the significance of the difference. Table 4 displays the results obtained. The results show that the mean Masculinity measure for men is significantly higher than that of women, while the opposite is true for the construct Femininity. With regards to the three constructs Recognition, Entitlement, and Apprehension, only in the case of Entitlement is the difference between the means of both groups significant (at the $p<0.05$ level) with men having a higher mean than women, thus indicating that they have a higher sense of entitlement. 


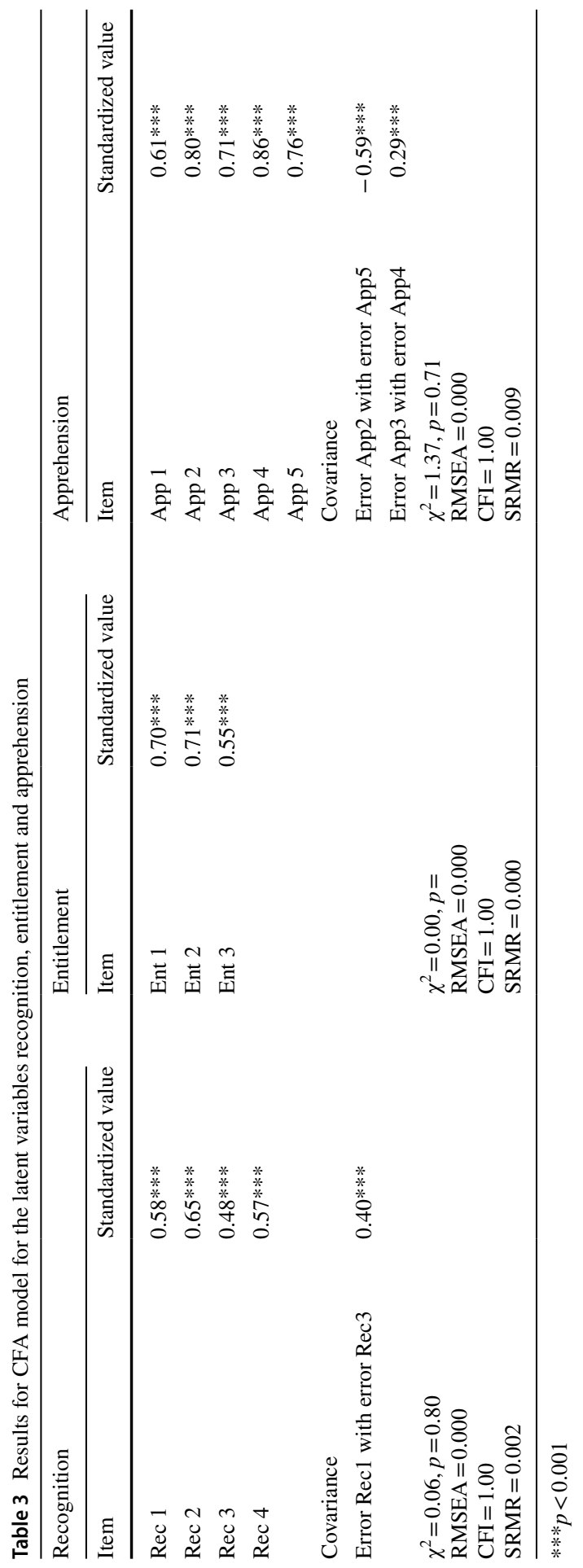


Table 4 Testing for differences in means between males and females

\begin{tabular}{|c|c|c|c|c|c|c|c|}
\hline Model & Women & Men & $\chi^{2}(\mathrm{df})$ & RMSEA & CFI & SRMR & Effect size \\
\hline Masculinity & 0 (constrained) & $0.36^{* * * *}$ & $\begin{array}{r}41.67(14) \\
p<0.001\end{array}$ & 0.104 & 0.910 & 0.061 & 0.45 \\
\hline Femininity & 0 (constrained) & $-0.29 * * *$ & $\begin{array}{r}58.29(23) \\
p<0.001\end{array}$ & 0.094 & 0.943 & 0.051 & -0.35 \\
\hline Recognition & 0 (constrained) & -0.14 & $3.14(5), p=0.68$ & 0.00 & 1.00 & 0.007 & -0.18 \\
\hline Entitlement & 0 (constrained) & $0.23 *$ & $0.97(2), p=0.62$ & 0.00 & 1.00 & 0.007 & 0.22 \\
\hline Apprehension & 0 (constrained) & -0.11 & $10.12(10), p=0.43$ & 0.008 & 1.00 & 0.012 & -0.11 \\
\hline
\end{tabular}

$* p<0.05, * * * p<0.001$

We also calculated the effect size for the differences in the mean between both gender by dividing the latent mean by the pooled standard deviation. The values obtained are shown in the last column of Table 4. The effect size for the constructs Masculinity and Femininity were found to be moderate while the effect size for the other three constructs were found to be weak.

\subsection{Model Building Using Structural Equation Modeling}

\subsubsection{Masculinity/Femininity and the Predictors of the Propensity to Initiate Negatiations}

The results obtained so far indicate that while there were gender differences in the constructs Masculinity and Femininity, no significant differences were found in Recognition and Apprehension. With regards to Entitlement, while a significant difference between the two genders was found, the effect size of that difference was weak, while the effect size of the gender differences in Masculinity and Femininity were found to be moderate. The three predictors of the propensity to initiate negotiation. In order to test the three hypotheses, we next investigated whether there is a relationship between the value of Masculinity and Femininity and an individual's likelihood of recognizing opportunities, feeling entitled, and feeling apprehensive towards negotiation. To do that, we fit three SEM models that following the structure shown in Fig. 1, where the construct "latent" represents either Recognition, Entitlement, or Apprehension.

Table 5 displays the results of fitting the three models separately. All three models have an acceptable fit with the RMSEA and the SRMR statistics less than 0.08 , and the CFI statistic greater than or equal to 0.90 . The table shows that both Femininity and Masculinity are positively associated with the construct recognition and that this association is significant at the $p<0.001$ level. Interestingly, the association between Femininity and Recognition is stronger than that between Masculinity and Recognition, indicating that traits that are considered to be feminine do not hamper an individual's ability to identify risks. In fact, our results indicate that these traits enhance the individual's ability. A Wald $\chi 2$ test of the difference of both path coefficients reveals a $p$ value of 0.15 , indicating that the 


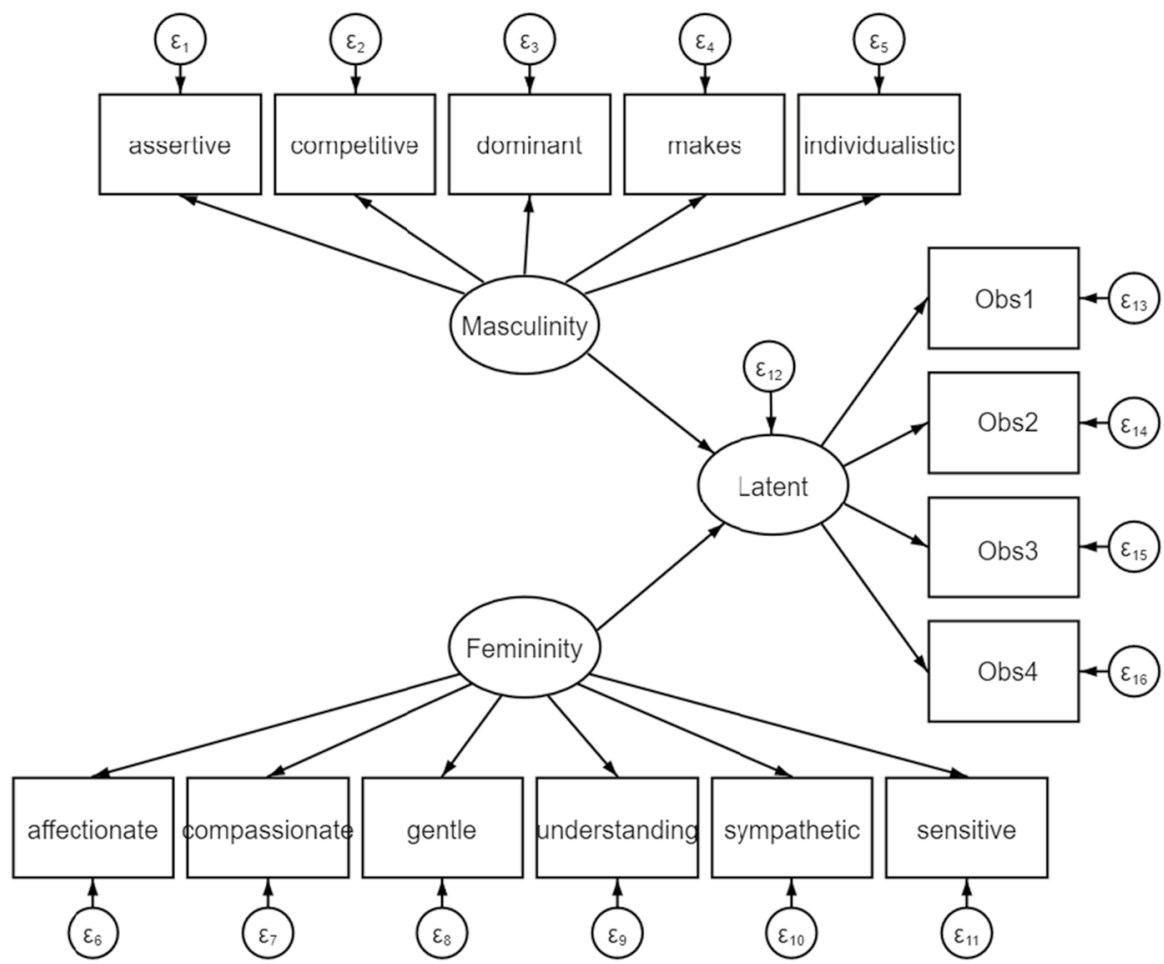

Fig. 1 SEM investigating the relationship between Masculinity/Femininity and between the constructs Recognition, Entitlement, and Apprehension

Table 5 Coefficients of the path from Femininity and Masculinity in the SEM model to each latent variables and the goodness-of-fit statistics

\begin{tabular}{|c|c|c|c|c|c|c|}
\hline \multirow[t]{2}{*}{ Model } & \multicolumn{2}{|c|}{ Standardized path coefficient } & \multirow[t]{2}{*}{$\chi^{2}(\mathrm{df})$} & \multirow[t]{2}{*}{ RMSEA } & \multirow[t]{2}{*}{ CFI } & \multirow[t]{2}{*}{ SRMR } \\
\hline & Femininity & Masculinity & & & & \\
\hline Recognition & $0.43 * * *$ & $0.24 * * *$ & $191.96(86), p<0.001$ & 0.059 & 0.921 & 0.062 \\
\hline Entitlement & -0.04 & $0.33^{* * *}$ & $203.21(74), p<0.001$ & 0.071 & 0.90 & 0.063 \\
\hline Apprehension & $0.17 * *$ & -0.02 & 178.53(99), $p<0.001$ & 0.048 & 0.956 & 0.055 \\
\hline
\end{tabular}

$* p<0.05, * * p<0.01, * * * p<0.001$

difference is not significant, leading us to reject hypothesis 1 . With regards to the construct Entitlement, our results indicate that masculinity is significantly associated with having a sense of entitlement, in support of hypothesis 2 , while the result for Femininity is negative, very small, and not significant. Finally, we see that Femininity is significantly associated with Apprehension at the $p<0.01$ level (supporting hypothesis 3), while the coefficient for Masculinity is negative, very small, and not significant. 


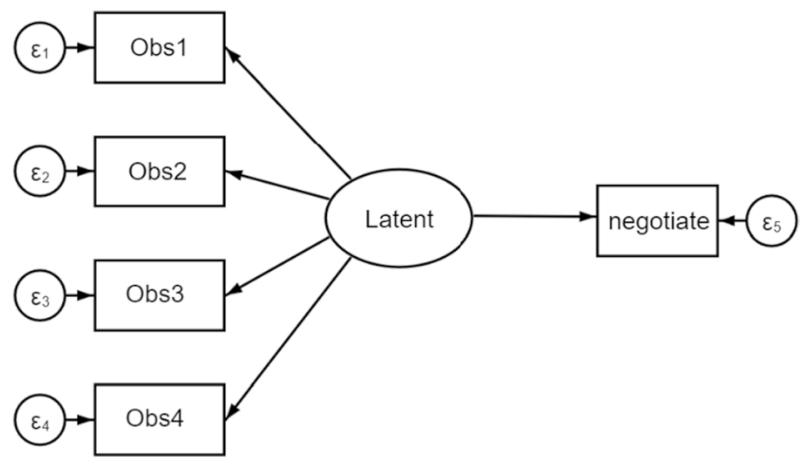

Fig. 2 SEM investigating the relationship between the constructs Recognition, Entitlement, and Apprehension on one hand and between the negotiation measure on the other hand

Table 6 Coefficient of each latent variable in the SEM model with negotiation as the dependent variable and the goodness-of-fit statistics

\begin{tabular}{lcllll}
\hline Model & $\begin{array}{l}\text { Standardized path } \\
\text { coefficient }\end{array}$ & $\chi^{2}(\mathrm{df})$ & RMSEA & CFI & SRMR \\
\hline Recognition & $0.39^{* * *}$ & $1.24(4), p=0.87$ & 0.000 & 1.000 & 0.009 \\
Entitlement & $0.28^{* * *}$ & $1.21(2), p=0.55$ & 0.000 & 1.000 & 0.014 \\
Apprehension & $-0.14^{*}$ & $3.22(7), p=0.87$ & 0.000 & 1.000 & 0.014 \\
\hline
\end{tabular}

$* p<0.05, * * p<0.01, * * * p<0.001$

\subsubsection{The Predictors of the Propensity to Initiate Negotiate and the Act of Negotiation}

The above results support the second and third hypotheses. In addition, the results discussed so far also constitute the first building block in our model. Now that the link between Masculinity and Femininity on the one hand and the three predictors of the propensity to negotiate on the other has been established, we next sought out to investigate whether the three constructs Recognition, Entitlement, and Apprehension are associated with negotiation behavior. In order to do that we again fit three different models following the structure shown in Fig. 2 where the variable "latent" represents one of the three constructs and the variable negotiate, as discussed previously, is measured by the item "How often do you initiate negotiations with the people with whom you work." The results of fitting the three models are displayed in Table 6.

Both Recognition and Entitlement are positively associated with the variable negotiate while Apprehension is negatively associated with it. The first two are significant at the $p<0.001$ level, while the third is significant at the $p<0.05$ level. All goodness-of-fit statistics indicate that the three models are well fit. These results indicate that individuals who are able to recognize opportunities more, who have a sense of entitlement, and who have little apprehension towards the act of negotiation are the ones who negotiate the most. 


\subsubsection{The Final Model}

The results obtained so far in the study indicate that:

- Men score higher on Masculinity then women

- Women score higher on Femininity than men

- Both masculine and feminine traits are positively and significantly associated with recognizing opportunities

- Only masculine traits are positively and significantly associated with having a sense of entitlement

- Only feminine traits are positively and significantly associated with feeling apprehension towards negotiation

Given the above, a model that seeks to explain differences between individuals who score high on masculinity and those who score high on femininity must encompass the differing effects that Masculinity and Femininity have on Recognition, Entitlement, and Apprehension, and how Entitlement and Apprehension have, in their turn, differing effects on negotiation. Figure 3 displays the model and shows the output obtained from fitting it to the data ${ }^{1}$ (please see footnote for an explanation as to why the construct Recognition was not included in the model). The model includes the finding that Masculinity leads to a higher sense of Entitlement, which in turn leads to more negotiation on behalf of the individual. On the other hand, Femininity leads to a higher feeling of Apprehensiveness, which decreases the likelihood of negotiation. Looking at the goodness-of-fit statistics, we see that both the SRMS and the RMSEA are less than 0.08 indicating a well fit model. The CFI is 0.90 which is the borderline value for an acceptable model. The model includes the correlations between the error items of the construct Apprehension when testing the goodnessof-fit of the initial constructs. All item loadings are significant at the $p<0.001$ level, and the majority of these loadings have a magnitude that is greater than 0.6. The standardized path coefficient from Masculinity to Entitlement is 0.34, and the coefficient from Entitlement to negotiate is 0.32 . Both are significant at the $p<0.001$ level. The standardized path coefficient from Femininity to Apprehension is 0.17, while the coefficient from Apprehension to negotiate is -0.17 . Both are significant at the $p<0.01$ level.

\footnotetext{
${ }^{1}$ We initially fit a model that included the construct Recognition. We included paths from both Masculinity and Femininity to this construct, since our results indicated that both significantly contributed to Recognition. We also included a path from Recognition to the variable negotiate. All three paths were found to be positive and significant at the $p<0.001$, thus indicating that Recognition enhances negation and that both Masculinity and Femininity contribute positively to Recognition. All other path coefficients and significance remained almost the same. However, the CFI of the model was only 0.865 , and the SRMR and the RMSEA were both greater than the ones obtained for the model in Fig. 3. Therefore, we have included the model that resulted in an acceptable fit.
} 


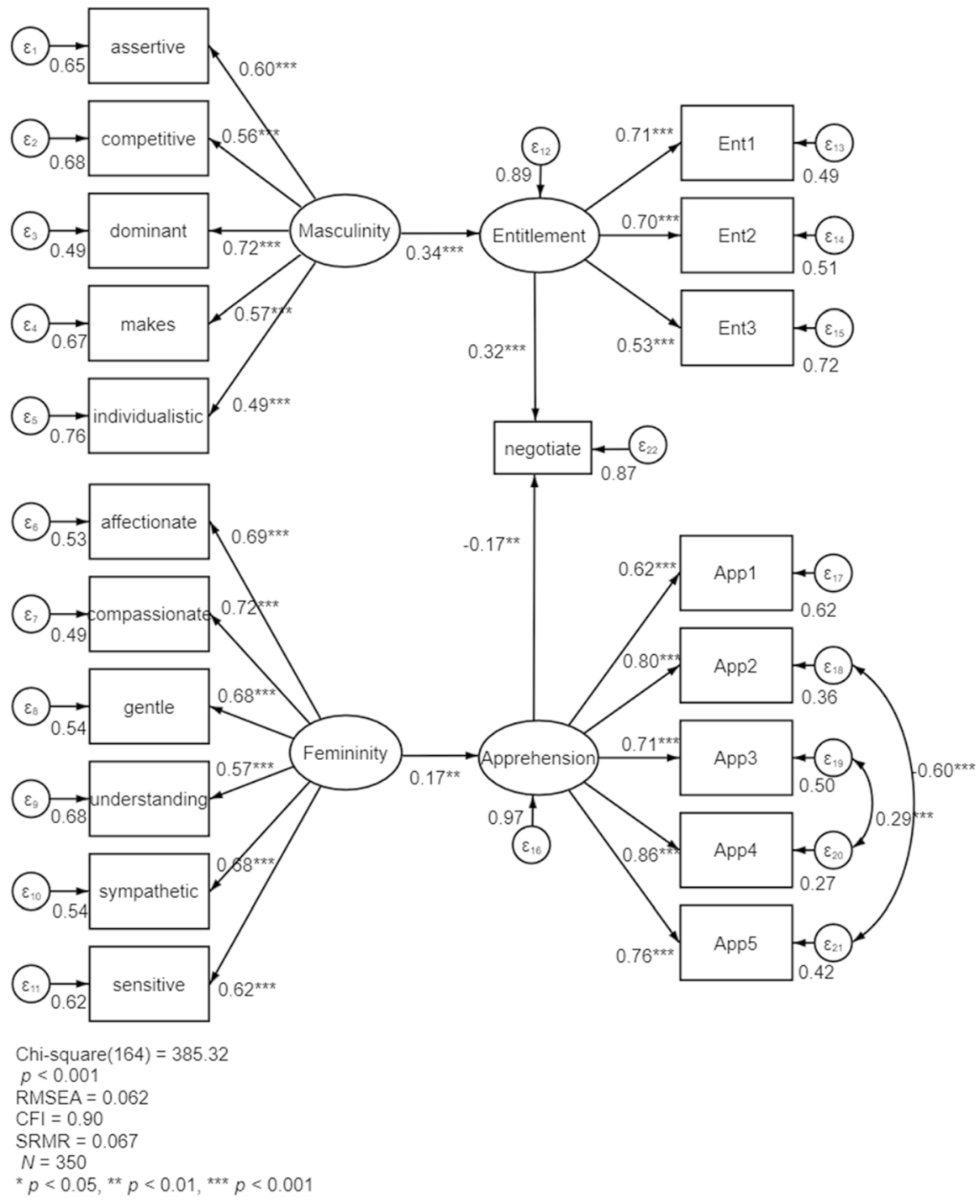

Fig. 3 Final model that incorporates how Masculinity is positively associated with Entitlement which is positively associated with negotiation while Femininity is positively associated with Apprehension which is negatively associated with negotiation

\subsubsection{Direct and Indirect Effects of Sex}

In order to investigate the direct and indirect effects that biological sex might have on the four constructs, Masculinity, Femininity, Entitlement, and Apprehension, we refit the above model, only this time we included a path from the variable sex to each of the constructs. The standardized path coefficients from sex to each construct are shown in Fig. 4. 


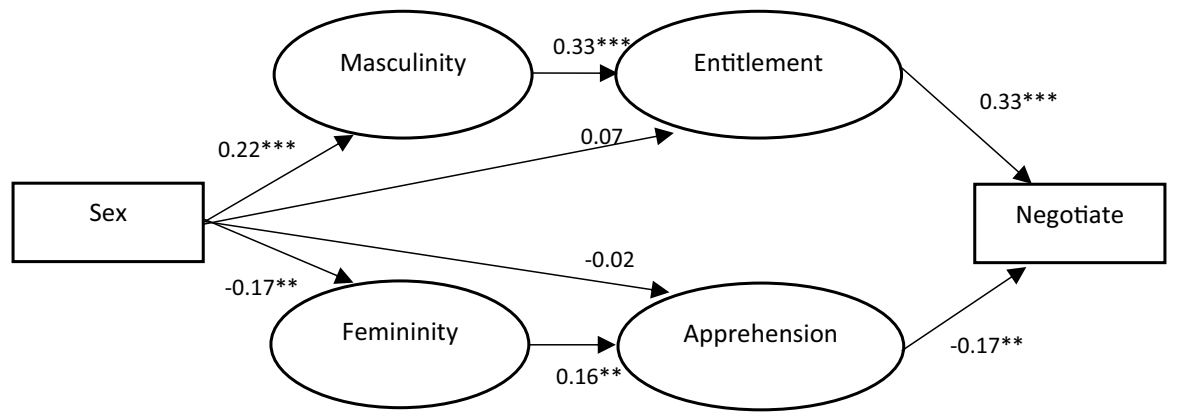

Fig. 4 Coefficients of the path from sex to Masculinity, Femininity, Entitlement, and Apprehension

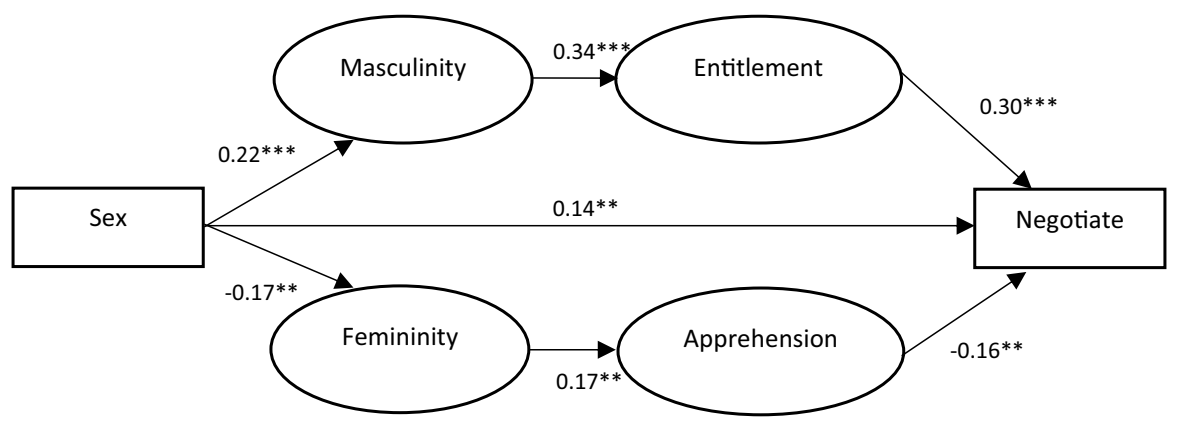

Fig. 5 Coefficients of the path from sex to Masculinity, Femininity, and negotiate

The result was that the coefficients of the paths from sex to each of Entitlement and Apprehension were not significant. With regards to the coefficient from sex to Masculinity, the standardized coefficient was found to be 0.22 and significant at the $p<0.001$ level, while the standardized coefficient from sex to Femininity was found to be -0.17 and significant at the $p<0.01$ level. This result indicates that the effect of sex on both Entitlement and Apprehension is indirect and is mediated by Masculinity and Femininity. Given that the higher value of sex was associated with men in our dataset, these results mean that men were more masculine and less feminine than women. However, it should be noted that the inclusion of sex into the structural equation model decreased the fit of the model, with the CFI dropping from 0.90 to 0.88 , which is below the threshold value of 0.90 that is used to indicate an acceptable model fit.

We next refit the model, but this time we included a path from sex to the constructs Masculinity and Femininity while also including a path from gender to the variable negotiate. The purpose was to investigate whether the effect of sex on negotiation is mediated by Masculinity and Femininity, given the fact that the mean value of negotiation for men was higher than the mean value for women. The standardized path coefficients from sex to each construct is shown in Fig. 5. 
As expected, the path from sex to Masculinity was positive and statistically significant, and the path from sex to Femininity was negative and statistically significant, thereby indicating that men were higher on masculinity and lower on femininity. The interesting finding was that the path from sex to negotiate was positive and statistically significant at the $p<0.01$ level, where the standardized path coefficient was found to be 0.14. It is important to note that the paths from Entitlement and Apprehension to the variable negotiate retained their value and their significance. This means that the effect of sex on negotiation was not completely mediated by Masculinity and Femininity. However, it should be noted that the goodness of fit of the model dropped. The CFI of this model is 0.885 , which is below the 0.90 cutoff value, and the SRMR is 0.088 , which is above the cutoff value of 0.08 .

\section{Discussion}

Traditionally, studies about gender differences in negotiation divided subjects based on biological sex. The results obtained in those studies indicated that women do not perform as well as men in negotiations, at least in certain contexts. These results were explained using gender role theories, where it was argued that men possess more agentic qualities while women possessed more communal characteristics (Paddock and Kray 2011). Our study extends the findings of previous research in two ways. First, we take the logical step of measuring the constructs masculinity and femininity instead of relying on the male/female dichotomy. By doing so, we were able to investigate how certain psychological characteristics enhance or impede the likelihood of negotiation.

Our results clearly show that qualities that are traditionally associated with men enhance an individual's sense of entitlement, which in turn increases the likelihood of the individual engaging in negotiation. At the same time, qualities that are traditionally associated with women impede individuals due to an increased level of apprehension, which decreases the likelihood of an individual engaging in negotiations. This apprehension is theorized to be due to individuals not wanting to overstep their social boundaries (Eagly and Karau 2002). Our results provide support for the idea that women need to adopt certain masculine traits in order to increase the likelihood of engaging in negotiations. An important point illustrated by our findings is that the construct femininity had a larger standardized path coefficient than the construct masculinity when modeling the latent variable recognition, but the difference was not found to be significant. This result indicates that less emphasis needs to be put on training women to identify contexts in which they can negotiate. Women do not need to adopt masculine traits to identify opportunities. Instead, the effort should be directed at enhancing women's sense of entitlement and decreasing their apprehension to negotiation. Since the social role of women is associated with communality (Eagly and Wood 1999), many women are more likely to be apprehensive towards negotiation because, in many instances, negotiation is a tool to further one's interest whether these interests are career or salary-related (O'shea and Bush 2002; Stevens et al. 1993). The result is that many women refrain from negotiating to further their self-interest (Wade 2001). 
The male social role, on the other hand, is associated with agency, and this enhances their sense of entitlement. Individuals who value power and money tend to see themselves as entitled to these things, especially when the highest positions in the social structure around them are occupied by individuals similar to them (Hogue et al. 2007). In such conditions, assumptions about the worthiness of certain actors lead to more general assumptions about the worthiness of whole categories of social actors (Ridgeway et al. 1998). Studies across multiple domains have found that men have a higher sense of entitlement than women (Hogue et al. 2007; Pryor et al. 2008). Our results show that individuals with masculine traits do have a higher sense of entitlement when it comes to negotiation and that this heightened sense of entitlement is associated with higher levels of negotiating behavior.

These results are problematic in the sense that they indicate that to reduce the negotiation gap between men and women, women need to adopt certain masculine characteristics, which, as other researchers have clearly documented, would cause them to suffer from social backlash (Amanatullah and Tinsley 2013). Although negotiation training is useful (Movius 2008; Stevens et al. 1993), our results suggest that a reconceptualization of social roles (Diekman and Eagly 2000 ) is a necessary condition to bridging the negotiation gender gap. While the results indicate that women need to be willing to overstep their traditional social roles in order to increase their likelihood of initiating negotiations, it is important to note that if they choose to do so they would be violating injunctive norms (Stuhlmacher and Linnabery 2013). This means that for women to be truly able to do so, other members of society need to modify their understanding of social roles. This is especially true in societies, such as Lebanon, where strong distinctions exist between male and female roles (AHDR 2004; Khatib 2008), and were overstepping the boundaries of social roles might result in backlash.

This study also contributes to the literature by studying negotiation in a nonWestern country. Most of the studies cited in this paper have been conducted in North America, where the culture is classified as individualistic and masculine (Hofstede et al. 2010). However, there is reason to believe that these results are largely culture-dependent. Building on status construction theory (Ridgeway 1991), Cuddy et al. (2015) argued that people will attribute the most culturally valued traits to dominant groups. The study by Elgoibar et al. (2014) supported this by finding that worker representatives in the Netherlands accommodated more than their Spanish counterparts. Another study by Andersen et al. (2018) found that female sellers in a matrilineal society outperformed male sellers, and they did that while acting less aggressively than men. The results of the present study, which was conducted in Lebanon, a country that is classified as collectivist and masculine (Hofstede et al. 2010), support the general findings of studies conducted in North America. In short, men negotiate more than women due to the fact that they generally possess more masculine traits and less feminine traits, where masculine traits enhance the sense of entitlement, and feminine traits enhance the sense of apprehension. 


\section{Limitations}

This study is not without its limitations, the most significant being that the sample size is neither particularly large nor random. As such, future research should aim at trying to replicate the findings reported here. Another limitation is that while the final model had a CFI value of 0.90 , researchers are increasingly advised to use the value 0.95 in order to avoid the pitfalls of model misspecifications. In addition, Cronbach's alpha for the three items that measure entitlement was found to be 0.69 , which is below the cutoff value of 0.7 . It should also be noted that this is a study of correlations and not causality given the fact that structural equation modeling was used on a cross-sectional dataset.

\section{Appendix: Survey Items}

(1) Kindly indicate to what extent each of the following applies to you (1 to 7$)$ :

- Assertive

- Affectionate

- Competitive

- Dominant

- Compassionate

- Understanding

- Gentle

- Individualistic

- Makes decisions easily

- Sympathetic

- Sensitive

(2) Kindly indicate to what extent you agree or disagree with the following (1 to 7):

- Most things are negotiable.

- Many interactions I have during the day can be opportunities to improve my situation.

- There are many things available to people, if only people asked for them.

- I often see chances to improve my situation.

- I think situations should be changed to fit my desires.

- I usually feel that I have earned the right to have things go my way.

- Just because I want something, it doesn't mean I am entitled to get it (reverse coded).

- I feel anxious when I have to ask for something I want.

- It always takes me a long time to work up the courage to ask for things I want.

- I feel nervous when I am in situations in which I have to persuade others to give me things that I want.

- I experience a lot of stress when I think about asking for something I want.

- It always feels unpleasant to have to ask for things for myself. 
(3) How often do you initiate negotiations with the people with whom you work (1 to 7)?

(4) How old are you?

(5) Kindly indicate your gender.

Funding Open access funding provided by the Qatar National Library. The authors declare that no funding was received for this research.

\section{Compliance with Ethical Standards}

Conflict of interest The authors declare that no conflict of interest exists.

Open Access This article is licensed under a Creative Commons Attribution 4.0 International License, which permits use, sharing, adaptation, distribution and reproduction in any medium or format, as long as you give appropriate credit to the original author(s) and the source, provide a link to the Creative Commons licence, and indicate if changes were made. The images or other third party material in this article are included in the article's Creative Commons licence, unless indicated otherwise in a credit line to the material. If material is not included in the article's Creative Commons licence and your intended use is not permitted by statutory regulation or exceeds the permitted use, you will need to obtain permission directly from the copyright holder. To view a copy of this licence, visit http://creativecommons.org/licen ses/by/4.0/.

\section{References}

Acock AC (2013) Discovering structural equation modeling using Stata. Stata Press, College Station AHDR: Arab Human Development Report (2004) Towards the rise of Women in the Arab World. United Nations Development Program: Regional Bureau for Arab States. National Press, Jordan

Amanatullah ET, Morris MW (2010) Negotiating gender roles: gender differences in assertive negotiating are mediated by women's fear of backlash and attenuated when negotiating on behalf of others. J PersSocPsychol 98:256-267. https://doi.org/10.1037/a0017094

Amanatullah E, Tinsley CH (2013) Punishing female negotiators for asserting too much... or not enough: exploring why advocacy moderates backlash against assertive female negotiators. Organ Behav Hum Decis Process 120:110-122. https://doi.org/10.1016/j.obhdp.2012.03.006

Andersen S, Ertac S, Gneezy U, List JA, Maximiano S (2018) On the cultural basis of gender differences in negotiation. Exp Econ 21(4):757-778. https://doi.org/10.1007/s10683-017-9547-y

Austin W, McGinn NC, Susmilch C (1980) Internal standards revisited: effects of social comparisons and expectancies on judgments of fairness and satisfaction. J ExpSocPsychol 16:426-441. https://doi. org/10.1016/0022-1031(80)90049-9

Babcock L, Laschever S (2009) Women don't ask: negotiation and the gender divide. University Press, Princeton

Babcock L, Gelfand M, Small D, Stayn H (2006) Gender differences in the propensity to initiate negotiations. In: De Cremer D, Zeelenberg M, Murninghan K (eds) Social psychology and economics. Psychology Press, New York, pp 239-259

Bandura A (1977) Social learning theory. Prentice-Hall, Englewood Cliffs

Barnes LB (1981) Managing the paradox of organizational trust. Harvard Bus Rev 59:107-116

Bazerman MH, Moore DA (2008) Judgment in managerial decision making. Wiley, New York

Bazerman MH, Curhan JR, Moore DA, Valley KL (2000) Negotiation. Annu Rev Psychol 51:279-314. https://doi.org/10.1146/annurev.psych.51.1.279 
Bem SL (1974) The measurement of psychological androgyny. J Consult ClinPsychol 42:155. https://doi. org/10.1037/h0036215

Blount S, Bazerman MH (1996) The inconsistent evaluation of absolute versus comparative payoffs in labor supply and bargaining. J Econ Behav Organ 30:227-240. https://doi.org/10.1016/S0167 -2681(96)00891-8

Bowles HR, Kray LJ (2013) Negotiation is a man's game: Ultimate truth or enduring myth. In: Gender \& work: challenging conventional wisdom. Harvard Business School Press, Cambridge

Bowles HR, Babcock L, McGinn KL (2005) Constraints and triggers: situational mechanics of gender in negotiation. J PersSocPsychol 89:951-965. https://doi.org/10.1037/0022-3514.89.6.951

Bowles HR, Babcock L, Lai L (2007) Social incentives for gender differences in the propensity to initiate negotiations: sometimes it does hurt to ask. Organ Behav Hum Decis Process 103:84-103. https:// doi.org/10.1016/j.obhdp.2006.09.001

Brooks AW, Schweitzer ME (2011) Can nervous nelly negotiate? How anxiety causes negotiators to make low first offers, exit early, and earn less profit. Organ Behav Hum Decis Process 15(1):43-54. https://doi.org/10.1016/j.obhdp.2011.01.008

Buss DM (1995) Psychological sex differences: origins through sexual selection. Am Psychol 50(3):164168. https://doi.org/10.1037/0003-066X.50.3.164

Bussey K, Bandura A (1999) Social cognitive theory of gender development and differentiation. Psychol Rev 106(4):676-713. https://doi.org/10.1037/0033-295X.106.4.676

Bylsma WH, Major B (1992) Two routes to eliminating gender differences in personal entitlement: social comparisons and performance evaluations. Psychol Women Q 16(2):193-200. https://doi. org/10.1111/j.1471-6402.1992.tb00249.x

Cuddy AJ, Wolf EB, Glick P, Crotty S, Chong J, Norton MI (2015) Men as cultural ideals: cultural values moderate gender stereotype content. J PersSocPsychol 109(4):622-635. https://doi.org/10.1037/ pspi0000027

Desmarais S, Curtis J (1997) Gender differences in pay histories and views on pay entitlement among university students. Sex Roles 37:623-642. https://doi.org/10.1007/BF02936332

Diekman AB, Eagly AH (2000) Stereotypes as dynamic constructs: women and men of the past, present, and future. PersSocPsychol Bull 26:1171-1188. https://doi.org/10.1177/0146167200262001

Eagly AH, Karau SJ (2002) Role congruity theory of prejudice toward female leaders. Psychol Rev 109:573-598. https://doi.org/10.1037/0033-295X.109.3.573

Eagly AH, Wood W (1999) The origins of sex differences in human behavior: evolved dispositions versus social roles. Am Psychol 54:408-423. https://doi.org/10.1037/0003-066X.54.6.408

Eagly AH, Wood W (2016) Social role theory of sex differences. In: Wong A, Wickramasinghe M, Hoogland R, Naples NA (eds) The wileyblackwell encyclopedia of gender and sexuality studies. Wiley, Chicester, pp 458-476. https://doi.org/10.1002/9781118663219.wbegss183

Eagly AH, Wood W, Diekman AB (2000) Social role theory of sex differences and similarities: a current appraisal. In: Eckes T, Trautner HM (eds) The developmental social psychology of gender. Erlbaum, Mahwah, pp 123-174

Eckel C, De Oliveira A, Grossman PJ (2008) Gender and negotiation in the small: are women (perceived to be) more cooperative than men? Negot J 24:429-445. https://doi.org/10.111 1/j.1571-9979.2008.00196.x

Elgoibar P, Munduate L, Medina FJ, Euwema MC (2014) Do women accommodate more than men? Gender differences in perceived social support and negotiation behavior by Spanish and Dutch worker representatives. Sex Roles 70(11-12):538-553. https://doi.org/10.1007/s11199-014-0378-4

Ely RJ, Stone P, Ammerman C (2014) Rethink what you "know" about high-achieving women. Harvard Bus Rev 92:100-109

Eriksson KH, Sandberg A (2012) Gender differences in initiation of negotiation: does the gender of the negotiation counterpart matter? Negot J 28(4):407-428. https://doi.org/10.111 1/j.1571-9979.2012.00349.x

Fontayne P, Sarrazin P, Famose JP (2000) The bem sex-role inventory: validation of a short version for French teenagers. Eur Rev ApplPsychol/Revue Européenne de PsychologieAppliquée 50:405-416

Helgeson VS (1994) Relation of agency and communion to well-being: evidence and potential explanations. Psychol Bull 116(3):412-428. https://doi.org/10.1037/0033-2909.116.3.412

Hofstede G, Hofstede GJ, Minkov M (2010) Culture and organizations: software of the mind. McGraw Hill Education, New York

Hogue M, Yoder JD, Singleton SB (2007) The gender wage gap: an explanation of men's elevated wage entitlement. Sex Roles 56:573-579. https://doi.org/10.1007/s11199-007-9199-Z 
Hu LT, Bentler PM (1999) Cutoff criteria for fit indexes in covariance structure analysis: conventional criteria versus new alternatives. StructEqu Model Multidiscip J 6:1-55. https://doi.org/10.1080/10705 519909540118

Johnson J, Repta R (2012) Sex and gender: beyond the binaries. In: Oliffe JL, Greaves L (eds) Designing gender, sex and health research. Sage, Thousand Oaks, pp 17-37

Kapalka GM, Lachenmeyer JR (1988) Sex-role flexibility, locus of control, and occupational status. Sex Roles 19(7-8):417-427. https://doi.org/10.1007/BF00289716

Katsurada E, Sugihara Y (1999) A preliminary validation of the Bem Sex Role Inventory in Japanese culture. J Cross Cult Psychol 30:641-645. https://doi.org/10.1177/0022022199030005005

Kennedy JA, Kray LJ (2015) A pawn in someone else's game? The cognitive, motivational, and paradigmatic barriers to women's excelling in negotiation. Res Organ Behav 35:3-28. https://doi. org/10.1016/j.riob.2015.09.002

Khatib L (2008) Gender, citizenship and political agency in Lebanon. Br J Middle East Stud 35:437-451. https://doi.org/10.1080/13530190802525189

Kolb DM (2009) Too bad for the women or does it have to be? Gender and negotiation research over the past twenty-five years. Negot J 25(4):515-531. https://doi.org/10.1111/j.1571-9979.2009.00242.x

Kray LJ, Thompson L (2004) Gender stereotypes and negotiation performance: an examination of theory and research. Res Organ Behav 26:103-182. https://doi.org/10.1016/S0191-3085(04)26004-X

Kray LJ, Thompson L, Galinsky A (2001) Battle of the sexes: gender stereotype confirmation and reactance in negotiations. J PersSocPsychol 80(6):942. https://doi.org/10.1037/0022-3514.80.6.942

Kray LJ, Galinsky AD, Thompson L (2002) Reversing the gender gap in negotiations: an exploration of stereotype regeneration. Organ Behav Hum Decis Process 87(2):386-409. https://doi.org/10.1006/ obhd.2001.2979

Kray LJ, Reb J, Galinsky AD, Thompson L (2004) Stereotype reactance at the bargaining table: the effect of stereotype activation and power on claiming and creating value. PersSocPsychol Bull 30:399411. https://doi.org/10.1177/0146167203261884

Kugler KG, Reif JA, Kaschner T, Brodbeck FC (2018) Gender differences in the initiation of negotiations: a meta-analysis. Psychol Bull 144(2):198-222. https://doi.org/10.1037/bu10000135

Kuther TL (1998) Sex and sex-role differences in locus of control. Psychol Rep 82(1):188-190. https:// doi.org/10.2466/pr0.1998.82.1.188

Leopold TA, Ratcheva V, Zahidi S (2016) The global gender gap report 2016. In: World economic forum.

Mazei J, Hüffmeier J, Freund PA et al (2015) A meta-analysis on gender differences in negotiation outcomes and their moderators. Psychol Bull 141:85-104. https://doi.org/10.1037/a0038184

McGann VL, Steil JM (2006) The sense of entitlement: Implications for gender equality and psychological well-being. In: Worell J, Goodheart CD (eds) Handbook of girls' and women's psychological health: gender and well-being across the lifespan. Oxford University Press, New York, pp 175-182

Movius H (2008) The effectiveness of negotiation training. Negot J 24:509-531. https://doi.org/10.111 1/j.1571-9979.2008.00201.x

Neale MA, Bazerman MH (1992) Negotiating rationally: the power and impact of the negotiator's frame. Executive 6:42-51. https://doi.org/10.5465/ame.1992.427418

Niederle M, Vesterlund L (2007) Do women shy away from competition? Do men compete too much? Q J Econ 122:1067-1101. https://doi.org/10.1162/qjec.122.3.1067

O'shea PG, Bush DF (2002) Negotiation for starting salary: antecedents and outcomes among recent college graduates. J Bus Psychol 16:365-382. https://doi.org/10.1023/A:1012868806617

Özkan T, Lajunen T (2005) Masculinity, femininity, and the Bem sex role inventory in Turkey. Sex Roles 52:103-110. https://doi.org/10.1007/s11199-005-1197-4

Paddock EL, Kray LJ (2011) The role of gender in negotiation. In: Benoliel M (ed) Negotiation excellence: successful deal making. World Scientific Publishing, Hackensack, pp 229-245. Retrieved from: https://triggered.clockss.org/ServeContent?url=http://baywood.stanford.clock ss.org\%2FBWWR\%2FBAWOOD_BWWR_16_2\%2F54516G021N4U2L21.pdf

Pfafman TM, McEwan B (2014) Polite women at work: negotiating professional identity through strategic assertiveness. Women's Stud Commun 37:202-219. https://doi.org/10.1080/07491409.2014.911231

Pryor LR, Miller JD, Gaughan ET (2008) A comparison of the psychological entitlement scale and the narcissistic personality inventory's entitlement scale: relations with general personality traits and personality disorders. J Pers Assess 90:517-520. https://doi.org/10.1080/00223890802248893

Putnam LL (1990) Reframing integrative and distributive bargaining: a process perspective. In: Lewicki RJ, Sheppard BH, Bazerman MH (eds) Research on negotiation in organizations. JAI Series Annual, JAI, Greenwich, pp 2-30 
Ridgeway C (1991) The social construction of status value: gender and other nominal characteristics. Soc Forces 70(2):367-386. https://doi.org/10.1093/sf/70.2.367

Ridgeway CL, Boyle EH, Kuipers KJ, Robinson DT (1998) How do status beliefs develop? The role of resources and interactional experience. Am Sociol Rev 63:331-350. https://doi.org/10.2307/26575 53

Rudman LA, Glick P (2001) Prescriptive gender stereotypes and backlash toward agentic women. J Soc Issues 57:743-762. https://doi.org/10.1111/0022-4537.00239

Small DA, Gelfand M, Babcock L, Gettman H (2007) Who goes to the bargaining table? The influence of gender and framing on the initiation of negotiation. J PersSocPsychol 93:600-613. https://doi. org/10.1037/0022-3514.93.4.600

Stevens CK, Bavetta AG, Gist ME (1993) Gender differences in the acquisition of salary negotiation skills: the role of goals, self-efficacy, and perceived control. J ApplPsychol 78:723. https://doi. org/10.1037/0021-9010.78.5.723

Stuhlmacher AF, Linnabery E (2013) Gender and negotiation: a social role analysis. In: Olekalns M, Adair W (eds) Handbook of research on negotiation research. Edward Elgar, London, pp 221-248. https://doi.org/10.4337/9781781005903.00018

Stuhlmacher AF, Walters AE (1999) Gender differences in negotiation outcome: a meta-analysis. PersPsychol 52:653-677. https://doi.org/10.1111/j.1744-6570.1999.tb00175.x

Stuhlmacher AF, Citera M, Willis T (2007) Gender differences in virtual negotiation: theory and research. Sex Roles 57:329-339. https://doi.org/10.1007/s11199-007-9252-y

Tellhed U, Björklund F (2011) Stereotype threat in salary negotiations is mediated by reservation salary. Scand J Psychol 52:185-195. https://doi.org/10.1111/j.1467-9450.2010.00855.x

Thompson MS, Green SB (2006) Evaluating between-group differences in latent variable means. In: Hancock GR, Mueller RO (eds) A second course in structural equation modeling. Information Age, Greenwich, pp 119-169

Thompson L, Loewenstein G (1992) Egocentric interpretations of fairness and interpersonal conflict. Organ Behav Hum Decis Process 51:176-197. https://doi.org/10.1016/0749-5978(92)90010-5

Tsay CJ, Bazerman MH (2009) A decision-making perspective to negotiation: a review of the past and a look to the future. Negot J 25:467-480. https://doi.org/10.1111/j.1571-9979.2009.00239.x

Volkema RJ, Fleck D (2012) Understanding propensity to initiate negotiations: an examination of the effects of culture and personality. Int J ConflManag 23(3):266-289. https://doi.org/10.1108/10444 061211248976

von Hippel C, Wiryakusuma C, Bowden J, Shochet M (2011) Stereotype threat and female communication styles. PersSocPsychol Bull 37:1312-1324. https://doi.org/10.1177/0146167211410439

Wade ME (2001) Women and salary negotiation: The costs of self-advocacy. Psychol Women Q 25:6576. https://doi.org/10.1111/1471-6402.00008

Walters AE, Stuhlmacher AF, Meyer LL (1998) Gender and negotiator competitiveness: a meta-analysis. Organ Behav Hum Decis Process 76:1-29. https://doi.org/10.1006/obhd.1998.2797

Publisher's Note Springer Nature remains neutral with regard to jurisdictional claims in published maps and institutional affiliations. 